\title{
Music and Performance as Sonic Acts of Political Struggle; Counter-Political Soundscapes in Urban Realm
}

\author{
Konca Sahera, Murat Cetina
}

\begin{abstract}
The paper takes the relation between soundscapes and power struggles as its problem area and focuses on the role of music that is performed in public protests. It argues that music and street performances are conceived and therefore utilised as sonic acts of political struggle in urban realm. Starting with a general understanding of hearing mechanisms, the study elucidates the relationships among territoriality of soundscape, identity construction, social segregation and polarisation, and finally, power struggle. Within the framework of the intersection area of these concepts, the paper discusses the processes of politisation of soundscape through music as a form of protest event that is performed in public realm. Throughout the paper, it is focused on the significant cases of public protests as well as political events that occured in public space. The main emphasis is on the use of sound technologies to impose power on masses of people. The paper tackles the question of how the salient characteristics of soundscape are sonically adopted as means for counter-political acts in public realm.
\end{abstract}

\section{Keywords}

Politics of sound, urban acoustics, soundscape

The paper discusses the role of music and street performances as sonic acts of political struggle in urban realm within the framework of the power relationships between soundscape and public space. These acts and their auditory dimensions are tackled as counter-political soundscapes in urban spaces throughout this paper. The paper aims to find answers to the question of how the audio-spatial characteristics of soundscape are sonically appropriated as means for counter-political acts (particularly in form of public spectacles, a crucial part of which is music) in urban realm. With a specific focus on music used in public protests, the paper discusses sound and the associated soundscape as a way of expressing identity, and particularly a communal identity whether it is a social class, or an ethnic group, or a political organisation.
The paper problematizes the notion of the relation between "sound and power" and its reflection on the sound-related activities in public spaces. The paper argues the "territoriality of sound" as one of its attributes that perpetuate existing dynamics of social segregation. It develops the primary argument that sound emerges as another layer of media for ongoing socio-political struggles as a consequence of such segregation and polarisation. Along this path, the paper reviews evolution of sound-in the context of the phenomenology of power-space relations-from a

aKadir Has University, Istanbul, Turkey

Correspondent Author:

Murat Cetin, Faculty of Art \& Design, Kadir Has University, Cibali Campus, Cibali, Istanbul, 34083 Turkey 
psychological manouvering device to manipulate masses to a counter-political device not only for self-expression of identity, but also as a shield (if not a weapon) of resistance to segregation and suppression.

Thus, the paper is structured in a sequence of a review of "sound and its attributes" as a phenomenon of human perception developing into a very strong leverage to control, segregate, and suppress people on the basis of their socio-political classes; firstly, starting from understanding sound, its mechanisms of perception, its dissemination and digital transformation; secondly, discussing the changing position of sound in controlling or developing counter-political strategies in urban realm; thirdly, examining the role of musical and performative events as unique means for expressing identity of various (and sometimes conflicting) communities in urban space; and finally, arguing the relation between the territoriality of sound as a medium of identity and its use for class-based social segregation that physically manifests itself in urban space.

\section{UNDERSTANDING SOUND, ITS MECHANISMS AND ITS EVOLUTION ALONG THE PATH OF BECOMING A (SONIC) ACT OF POLITICAL STRUGGLE}

At this point, it is of interest, firstly, to understand, how humans hear sounds and how they are psychologically affected by this hearing process, and how the knowledge on hearing and its impacts on individuals have been exploited within sociological framework towards a broader conception of its relation to power struggles in urban realm. Along this purpose, the problem of "sound", and its derivative "music as a political tool in urban space" are tackled on three complementary tracks; the first of which is the role of hearing mechanisms on power exertion in public realm, the second of which is on mechanisms of hearing and their influence on sound's becoming a public protest device through music, and finally third of which is the evolution of sound technologies towards their use as counter-political strategies of soundscape against the existing power mechanisms in urban realm.

\section{Human Hearing and the Power Exertion in Public Sphere via Sound}

In the context of the relationship between power and sound in public realm, how physical landscape and soundscape is shaped by those in power is emerging as the ultimate question. This paper concentrates on the audible dimension of the public realm during its use in public events and those which are publicly organised against the power in particular. Since one of the main institutions that can directly be associated with the power (or the central authority) is the police as the primary instrument of law enforcement (thus, power exertion) in public sphere, the relation of sound with the notion (or activities) of policing is of main interests in this paper before further discussing the role of sound in protesting against them. Obviously, the association of specific sounds with police is well known from police whistle to police sirens or from police walkie-talkies to security alarms, etc. These are typical sounds that clearly demonstrate the power in public domain especially in case of breaching the law. However, another, and perhaps even more significant issue is how sound is passively and constantly used by police to dominate the public realm causing a public reaction, leading to public protests, some of which are directly oriented against the audible means that police utilises.

Chare (2011) emphasized the role of "listening" in policing since the inception of this profession. Parsons and Jesilow (2001), for instance, reminded us that police officers "signalled each other for help by rapping their clubs on the sidewalk or by blowing a whistle" before the introduction of the police radio to the scene. Hays (1992) added the notion of making noise (while listening to others) as an auditory indication of authoritarian intimidation (if not audio-violence) in public realm by drawing our 
attention to the "constant noise of the police radio, much of which is almost meaningless unless you know what to listen for and their language”. Moreover, audio surveillance has turned into an essential acoustic instrument of policing. Indeed, as Chare (2011) pointed out, collecting evidence by means of "listening in" or "wiretapping" is crucial in policing. Eventually, the audibility of criminals entraps them and the whirr or the click of handcuffs, which Freamon $^{1}$, as Chare (2011) cited, associates with success of policing, raises as the acoustic (and thus final) marker for an act of arrest. Besides, audio evidence is usually the foundation upon which many convictions are legally based. Thus, sound plays a crucial role in the establishment of power in public realm. Inevitably, reaction to the exertion of power by audiable means develops its counter-measures in form of public protests using sound in many ways as will be discussed below in detail.

\section{Mechanisms of Hearing and the Use of Spectacle as Protest via Music}

Various studies on hearing mechanisms, such as Gurney (1880), have revealed that the operation of human psychology is directly connected to human hearing mechanisms. It gives an account of the sensations of pleasure and pain in relation to human senses and discusses how listener differentiates between noise and tones through mechanisms of nerve stimulation. Thus, these mechanisms and their psychological outcomes are manipulated for controlling human reaction to soundscapes. It is discovered that certain frequencies were quite effective for certain types of feelings mainly due to the ratio of water in human body and its requirement for certain level of vibration. Certain machines and instruments are known to be accorded to certain frequency levels to be able to create social order or hysteria. Indeed, sounds may implant ideas of an "ethnic homogenous music practice". By the same token, they contest ideas of belonging, or borders between tradition and modernity. To be more specific, sounds evoke the feeling of inclusion or exclusion depending on how and where these mechanisms are adopted, which will later be linked with the discussions on "positioning of power". In that way, they may introduce notions of "Us" and the "Other" which may instigate some sorts of segregation in terms of locality, authenticity, belonging, identity, and nationality (Pistrick and Cyril 2013). Military music is a typical example of such attempts. Among many others, research on acoustical energy and its areas of use became very important during the eras of WWI and WWII. Thus, military knowledge was gradually transferred to corporate sector to stimulate and manipulate consumption. Eventually, controlling the accumulated knowledge on hearing mechanisms for being able to influence larger masses of people has become a known and legitimate phenomenon.

As Blesser and Salter (2006) discussed, we do have sonic shamans-priests of our modern society who can create powerful emotions among people with the sound of their voices or instruments as a social and cultural tool. The same applies to the architect who can be interpreted as an aural manipulator. Thompson (2002: 12) claimed that "the ephemeral quality of sound has long frustrated those who have sought to control it”, referring to the architect Rudolph Markgraf who expressed his frustrations when he complained in 1911 that "sound has no existence, shape or form, it must be made new all the time, it slumbers until it is awakened, and after it ceases its place of being it is unknown". Indeed, historians of soundscapes are challenged by sound's mysterious ability to melt into air like Markgraf who was perplexed by "the mysteries of the acoustic" which stimulated various researches ranging from the role of sounds on computer games to use of gender based sounds in public anouncements. These researches may shed light into studies regarding the relation between soundscape and its political uses on humans in architectural spaces. For instance, there are various 
studies on the effects of game sounds on emotions (such as which type of sounds triggers the feelings of fear, anxiety, and suspense) showing the role of sound design in manipulating human emotions. Specifically, either "high volume sounds" or "timed sound effects" seem to be the best type of sound design for creating the feelings of fear. Moreover, "medium-volume sound effects" appear as the most appropriate type of sound design for causing the feeling of anxiety (Toprac and Meguid 2011).

In the light cast by the discussions above, hearing mechanisms seem to be well understood to control the crowd dynamics in public realm. Before delving into the question of how exploitation of human hearing mechanisms by both authorities and protesters is reflected as music or spectacles in public urban spaces, it is of utmost significance to understand the role of special soundscapes created by certain (identity) groups in the management of these crowds. Monaghan and Walby (2012) suggested that noise (such as whistles, yelling, air horns, fireworks, even songs and marches, etc.) is almost necessary to maintain the synergy and inertia in public protests. Particularly, the listening of music can promote sudden breakout of energy and enthusiasm within the groups of protesters, as does radical cheerleading to spectators. These emotional explosions can convey rather threatening message of power to the opposite side in a battle.

Regarding the exploitation of the hearing mechanisms in urban space, sound was also openly used in public areas to influence and manipulate people in terms of controlling their sense of belonging versus that of segregation. Peterson (2010) aspired toward anthropology of the city relying on experience of everyday life in the city. Along this path, Peterson questions how these downtown public performances are located in, connected to, and evoke the city, as well as how meaning is made in and around public performances. Thus, she aims to engage with grand performances as integrated into the urban fabric through their soundscapes. The grand performances such as concerts help produce the roles of urban actors through the physical organization of space, with the audience collectively organized in relation to, but separated from the performer, and through the practices required of all those involved (such as wider networks of programming, funding, and marketing). Peterson also explores the processes through which civic spaces and ethnic identities are created at downtown performances. Thus, Peterson opens up a discussion of the world of sound, musical performance, and a particular civic extravaganza within the frameworks of the politics of identity, urban planning, and the neoliberal world economy.

Indeed, those grand performances define unique soundscapes which can easily be associated with certain identities. To be more specific, for instance, street performances attract those who feel some sorts of association or sympathy with the identity underlying the performance (or the performers). In this regard, these performances (including the music and overall soundscape) have not only the distinguishing qualities but also, by the same token, the discriminatory potential. Along this path, Nightingale (2012) discussed the role of sound and music on social segregation. While sound and its properties can be used as spectacles to celebrate publicness (and thus freedom) in urban realm, it can also be used against the public which can be seen as a threat to those in power.

Jurgenson (2011), for instance, considered sound as a political tool for protests. Occupy Movements can be given as one of the best and particular examples of this sort. He asserts, however, that the potential of sound to be used for politics is fully abused both by protesters as well as by police against them. The political power struggle in the public realm manifests itself as tactics in the war of sounds between protesters and police forces of the government through various clash of noises; sometimes, for instance, human voices are joined in unison to be amplified as a powerful protest tool for expressing the participatory 
act of solidarity as a threat to those in power. The examples can be verified in a large spectrum ranging from strategic use of silence to crowd applause, chanting slogans, rhythmic beats of drums on the protesters' side, and sound of troops marching or LRAD (Long Range Acoustic Device) sonic weapon technologies that are used by police. In addition to use of "power of sight" against protesters through CCTV (Closed Circuit Television) cameras, surveillance towers, and helicopters, like in Foucault's "gaze" (Foucault 1980: 146-165), sound is used as a device to exert control over masses. Altogether, these can be considered as electronic version of panopticon particularly supported with computer databases that accommodate protesters' personal information.

On the one hand, in regard to the public protests that use sound (whether it is a human-mic or a specific piece of music performed by the public) as the leading figure, the examples below can be discussed. However, before delving into the specific instances, it must be emphasized that each of these examples proves that the air-occupation of such projected sound can not only dissolve the traditional boundaries of territoriality but also influence the communal mind. For instance, as Cluett (2013) argued, the use of Top-40 music by the CIA (Central Intelligence Agency) to encourage Manuel Noriega out of hiding in Panama in January 1990, or Janet Reno's use of Tibetan chant and Metallica in the 1993 Waco Texas incident and, most recently the use of the LRAD for crowd control at the 2009 G20 Summit in Pittsburgh, can all be perceived as the effects of atmo-terrorism. In fact, the purpose of LRAD was to guarantee that law enforcement commands can be easily heard by protesters despite their own noise (such as shouts, chants, and sirens). Similarly, as Cluett (2013) pointed out, Compound Security, in the case of UK's urban wars, deployed the High-Frequency Mosquito Device to keep young people out of public space. Interestingly enough, this tool was reinvented by young people as the Teen Buzz. It is basically a sound file which makes a constant high-pitched sound for challenging authority of adults. On a similar note, Radovic (2014) pointed out the essential role of "human microphone” in the 2011 Occupy Wall Street (OWS) movement particularly for amplifying the statements of speakers in those demonstrations. The law prohibited the use of megaphones, loudspeakers, or other electronic sound devices in protests by then. Thus, the human-mic was utilized by the occupiers, at the time as an organic public address system. O’Brien (2013) defined human-mic as a decidedly old-fashioned technique for amplifying speech through mass repetition that arose in response to regulations curtailing the use of amplified sound in Zuccotti Park.

Therefore, this practice can be seen as an attempt by occupiers to challenge the Government's monopoly on amplified public speech in New York which lasted approximately for 80 years. A deliberately sustained noisy public realm seems to be achieved by OWS for a certain amount of time, without being silenced by force due to the use of human-mic. As Arendt (1998) reminded us, "there is an important distinction to be made between violence and power: unlike power, which is actualized by individuals acting and speaking in concert, 'sheer violence is mute'”. Nonetheless, despite the sounds that were present at Zuccotti Park, a new repertoire of protest songs was felt missing as reporter James McKinley (2011) noted particularly moving from the motto "every successful movement has a sound track" that Tom Morello used in his interviews on OWS with other reporters. Indeed, as O’Brien (2013) pointed out, the long history of American "singing movements" has collectively created their own soundtracks. For instance, the American labor movement of the first decades of the twentieth century used printed song pamphlets and social gatherings like hootenannies to construct and consolidate the repertoire and musical practices of their movement. Likewise, the musicians and activists leading the Wisconsin Uprising deployed new technologies which served as a virtual 
hootenanny, convening in virtual spaces and relying on recordings and digital distribution both to attract sympathizers and to guide participants.

On the other hand, regarding the public protests that use sound technologies, the use of PA (Public Address) systems can be given as a typical example in regard to their first use for political purposes in amplifying the voices of candidates in their election speeches at the Republican and Democratic National Conventions in 1920. According to Radovic (2014), PA system was the main tool for political communication and brought an acoustical territory. From 1920s onwards, full permission (including issuing, denying, or revoking permits) for all types of amplified public speech was granted to the Police Commissioner. To be more specific, Police Commissioner was given the rights of both the use and the regulation of devices such as PA systems and batterypowered megaphone in all public spaces of the city (ranging from streets, parks, and squares to air and waters under its jurisdiction) at all times. As a matter of fact, Mitchell (2003) defined the permission of sound devices as the "liberalization of free speech". He adds that, by this process, "the object of legal restrictions has shifted from the content to the geography of speech”. Rather than limiting the content of protests, the goal of liberal speech regimes (through bureaucratic restrictions rather than outright bans) was to police where and at what volume the soundscape of protests was set. However, the unlimited right to use amplified sound in the public realm is held by the NYPD (New York Police Department) alone. In fact, it was witnessed, in 2011, with the forced eviction of OWS from Zuccotti Park. Despite Radovic (2014) perceived LRADs as "less-lethal" crowd control weapons, acoustically speaking, the extreme volume of the LRADs is actually an act of aural violence. Again, in regard to "less-lethal crowd control weapons”, Monaghan and Walby (2012) gave an account of G20 summits and noted new tactics of policing protests that have revived a series of coercive strategies. Scholars like Waddington and King (2007) as well as Zajko and Beland (2008) mentioned, for instance, snatch squads, no-go zones, no-face coverings at protests, etc. among these tactics. But the most striking one is the use of sound cannons. Similarly, the use of human voice by the security team of Turkish President as a sound-barrier to the voice of the protesters in Washington D.C. in the end of March $2016^{2}$ is a very recent and clear example of such "less-lethal" weapons.

Another exceptional example for controlling sound in urban public space is the case of Wisconsin Uprising, a movement of pro-labor activism that broke out in early 2011 in response to Wisconsin Governor Scott Walker's proposed union-busting "Budget Repair Bill” as O’Brien (2013) suggested. This movement was exceptional not only because it attracted many thousands of protesters to the State Capitol over weeks and culminated in recall elections for nearly a dozen elected officials of both parties, but also because it displayed innovative uses of music and sound in both live and mediated forms. Virtual and other mediated sonic performances were quite common. Protesters also created homemade music videos, audio recordings, and lyric sheets.

Seen from a Weberian perspective, as Radovic (2014) argued, the state (especially in the aforementioned case of the City of New York) legitimately owns the monopoly of the use of noise (i.e. amplified sound) just like it holds the monopoly of the use of physical violence. In sum, this spatialized struggle over sound has a significant impact on the right for public speech in public realm. The denial of citizens' (or a certain segregated segment of them) right to be involved in unquiet speech, means that the state also ignores citizens' right to be in a political realm that is not actually accepted by the state.

\section{Ramification of Sound Technologies as Instruments of Public Protest in Urban Space}

This section will tackle the question of how amplified 
sound functions within the public sphere. As known by now, the problem of the amplification of sound was the domain of architectural and instrumental acoustics. Therefore, increases in the volume (amplitude) of sound used to be the direct result of the properties of physical structures as well as the exertion of human physiology. Recently, however, sound technologies seem to transcend certain limitations of architectural and urban space. Johnson and Cloonan (2008) argued that technological devices which have proliferated and intensified during the twentieth century further empowered music to dominate public space. For instance, a single person could speak to thousands of people at a single time with the help of loudspeaker, which according to Cluett (2013) allowed Cicero's rhetoric (that is to say, the power and intimacy of orality in an efficient form of mass delivery) to be amplified. The effect of such a technology seems to shrink the dimension of the space that normally separates (and thus segregates) us by introducing a discourse of "speaking at a distance". Seen in this perspective, the asymmetry introduced by the loudspeaker through delivering unidirectional sound, presents a new dynamic of acoustic power. The loudspeaker enables speech to leave the confines of interior space and interior voice. Thus, it facilitates to convey speeches or music to the masses in the form of radio, concert venues, clubs, and home stereos, especially in the context of public addresses. Hence, the loudspeaker has the profound capacity to cross both physical and social borders, providing sound as well as music to be mobilized towards political ends mainly due to its ability to "present a single source to many".

Therefore, according to Cluett (2013), who is interested in power manifested socially in the form of surveillant control through carceral policies, the loudspeaker plays a leading role in the discourse of power as a part of the technical infrastructure of social listening. Indeed, his assertion that "the intersection of the technical affordances of the loudspeaker and a socially-conceived understanding of sound that a discourse of sound and power emerges” supports the argument developed in this paper. As Attali (1985) quoted, Hitler's statement that "without the loudspeaker we couldn't have conquered Germany” in a 1937 German Radio Manual, epitomizes the fact that "the amplified voices in public addresses have fundamentally changed the nature of 'the voice of authority'”. Doubtlessly, the audible aspect of power produces its counterpart by including sound in the struggles against the power. This point will be discussed below in detail.

The role of sound and its associated technologies in politics, as a demonstration of power on society, is also clear in the well-known election campaigns. Domousi and Deacon (2007) gave various examples from F. Roosvelt's use of radio in tackling the Great Depression to A. Hitler and his success in using radio as mentioned above. Recalling the incidence of Democrat candidate Al Smith's defeat by Herbert Hoover during the 1928 US elections, they relate the notion of power to effectiveness in mass mediation of their sound. Therefore, modernity can be seen as an era of neo-orality that serves the power.

Within such a deliberate context of manipulating soundscapes, McCartney (2010) asked whether those who make the soundscapes want to unveil unique sonic aspects of the place, or whether the creator of soundscape wants to establish an ideal place through sound. He further questions, if that is the case, what could be the salient features of such an imaginary "place". Thus, by which ideas and values this utopic creation would be conditioned is the ultimate question regarding the politics of soundscape. McCartney, in regard to the answers of these questions, shows how the composer treats the sounds by differentiating dominant sounds from masked sounds in the place and how he/she regulates their interaction with each other. One of the points that McCartney raised draws readers' attention to the issue of "listener's position" which is in parallel with the main argument of this 
paper. That is the question of whether the listener in space is imagined as ignorant and needing enlightenment, or assumed as having unique ways of listening. These assumptions can easily be located at the very heart of our discussion in regard to the ethics of auditory expression, and how these ethics are determined by underlying ideologies of sound and soundscape design. Particularly, in relation to the spatial and auditory dimensions of power and authority, how the users of a specific space are assumed, perceived, and treated (through mechanisms of spatial and auditory intelligence) are not only ethical but also political statements. In this context, Roland Barthes draws attention to the difference between what is heard and what is listened to, asserting that "hearing is a physiological phenomenon, listening is a psychological act. To listen is to decode, it is to make sense of a sensory input” (Barthes 1991).

At this stage where the relationship among power, control, space, and soundscape is established with reference to the theories given above, it is of interest to briefly explore the process of sound (as one of the most influential human senses) taking the form of "music" towards casting light over the discussions on how its leading role in reclaiming public realm has been exploited by protesters, which constitutes one of the major arguments of this paper. Therefore, in the next section, the role of music and performance as a political tool in urban space (particularly during public protests) will then be revealed and make more sense.

\section{MUSIC AND PERFORMANCE AS UNIQUE TYPES OF SOUND FOR SELF-EXPRESSING IDENTITY OF MASSES WITHIN THE CITY}

Returning back to the use of sound in public realm, the music, the spectacles, and other performative events emerge as the main auditory mechanisms to control urban space particularly after the rise of capitalism. Toth (2009) said that, according to Debord's powerful analysis, life is presented as an "accumulation of spectacles" in late capitalism. Such a "society of the spectacles" as a specific cultural form, as Attali (1985) suggested, is closely related to the mode of production in that society. Thus, the rise of sound and related spectacles in urban realm can be theorized as forms of "cultural disturbance in the silent and silenced deindustrialized space of late capitalism" (Attali 1985).

Moving from the music (as a form of sophistication or derivative of sound) as a political statement or act, the resistances and tensions (potential tools for and against capitalism) that music accommodates within itself are of interest in this part of the paper. According to Iles (2009), the birth of Noise Culture (which is a profoundly metropolitan genre that first emerged within the ravaged urban-industrial landscape particulary during the era of Thatcher and Reagan against which a profound reactionary cultural climate existed) can better be conceived in the context of the collapsed industrial city. Particularly, with the new regime of the "visible and audible rehabilitation" of the city from the late 1980's, early 1990's onwards, as Toth (2009: 31) stated, referring to music scholar Adam Krims (2007: 123), a new music-poetics has pointed out the "reconquest" of the city via this new genre. This new genre focused on issues such as: increasing rates of imprisonment (particularly for petty crimes), hysteria against immigrants, and presence of paramilitary groups in cities like New York and Paris.

In addition to the protest role the pop music and rock music play per se, the role of noise in the gentrification of run-down neighbourhoods (which is purely a political maneouver in terms of spatially relocating different classes within the urban space) is another dimension of the discussions regarding the role of sound in controlling urban space. In other words, such a newly injected noise type (in the form of soundscape of bars, cafes, and clubs) into an urban space, becomes the instrument of the expression of a new identity (of the new and elite people) that will 
replace the current inhabitants. Referring to Slater's (2009: 153) proposition that "the capital has transformed relations of production to embed our very senses in its architecture of valorisation”, Iles (2009: 10) suggested that urban gentrification following a path whereby noise is first introduced to the area to be gentrified. Initially, artists are positioned as placeholders on short leases to the area by the developers. Then, these areas are immediately populated by "noisy" bars and cafes so that they would soon become the destination for the city's new elite until the area becomes trendy and property values begin to climb. Then, not only artists' short term contracts are terminated but also locals who could not afford these properties are sent away for the area to be easily gentrified. Thus, sound is used as an instrument to control the demographics of an area in accordance with the spatial and architectural tools of urban transformation and urban gentrification. In this regard, sound seems to play a crucial role in class-based segregation of urban realm. In that sense, it becomes quite a political tool.

That is why public music and public performances play a vital role in the establishment of identities of powerful and counter-identities of the weaker segments of society. Thus, they both become political devices of struggle in public realm. In this context, the studies about the relationship between the nature of the music and the sonic dominance are of significance. For instance, as Hill (2012) reminded us, even before electronic sound amplification, composers like Wagner and Berlioz sought orchestral effects akin to sonic dominance. According to Schafer (1977), as referred by Hill (2012), their orchestras "were specially expanded to make possible a grandiloquent rhetoric, designed alternately to thrill, exalt and crush swelling metropolitan audiences”. In this regard, it is important to be able to understand and to interpret the mechanisms of perceiving music and performances from the point of "identity and place", because their relation with "sound" as a political tool binds the initial argument of the paper.

Consequently, the most important characteristic of the sound (particularly in form of public music and/or public performative event) appears to be its "territoriality" and its segregatory ramifications through its use for the benefit of the powerful minorities and at the peril of segregated masses. Therefore, the next section will look into the notion of the territoriality of sound as a medium of expressing identity.

\section{TERRITORIALITY OF SOUND AS A MEDIUM OF IDENTITY AND ITS USE FOR CLASS-BASED SOCIAL SEGREGATION}

This section will evaluate the territoriality of sound along two parallel tracks: firstly, the relation among sound, territory, and identity; later, the relation among music, identity construction, and social segregation.

\section{Sound, Territory, and Identity}

After aforementioned discussion of power-sound relationships, the initial argument of the paper is evolved into a phase whereby how sound creates its own identity and its associated space within urban realm should be discussed toward understanding how these two parallel processes are abused by those in power to segregate society according to classes using sound. Here, the intrinsic notion of the "territoriality of sound" plays a key role. In regard to the connection between voice and power, Johnson (2007) highlighted the key part that "voice" plays in defining territory and identity.

As argued by various scholars, sound has always been one of the rooted ways not only of defining territorial space, as well as encroaching on and enlarging it, but also of manifesting power (Johnson 2007: 113). The crucial role of manipulating sounds within the political agenda of the modernity project to control masses is recently noticed as can be seen in the words of Damousi and Deacon (2007: 1): 
The ubiquitous sound of gun-fire on the Australian gold-fields; the silence of men in the Citroën factory outside Paris as the giant drop-hammers boomed, the milling machines screamed, the boring machines squealed and the pulleys sighed; Australian schoolchildren reciting in one nation-wide accent; Alfred Deakin's virile oratory; William Tilly's dream of a "World English"; ideas of what was a "legitimate" or "pure" Australian accent; powerful speech, intimate speech and "bad English" in American talkies-the experience and meaning of these sounds and silences have seemed, until recently, too ineffable to be captured by historians.

Thus, sounds are directly associated by both the community that produces it and the immediate location that it is produced and, by this token, they directly are social markers of space. In regard to the role of sound as social signifier of space, Pistrick and Cyril (2013) brought about the issue of silences and asked the following questions: "In which sense does sound relate to sociality and silence to asocial behaviour? In which sense is sound perceived as a commodity and silence as a menacing factor?”. Referring to Sbardella's work on nuns' lives in a monastic Catholic context, Pistrick and Cyril claimed that the nuns' endeavour to keep their special soundcape contradicts with the relative freedom of lay people. This contradiction shows that soundscapes are social constructions conditioned by different collective realms. Silence is not "devoid of sense" yet meaningful as a highly symbolic resource which may refer to Foucauldian understanding of power (thus political) hierarchies (Foucault 1980).

At this point, Pistrick and Cyril (2013) further questioned whether soundscapes are deliberatly performative acts which are conditioned by particular socio-economic situation or they simply are cultural patterns, intrinsically pre-conditioned and connected to specific cultural background, or a habitus. Although it may be hard to answer this question, particularly when considering that sound-space relationship is flexible or constantly changing, above-mentioned discussions indicate that specific soundscapes are at least manipulated if not deliberately and totally redesigned by those in power and in control. Here, the "positioning of self" (Davies and Harré 1990: 43-63) gains significance in regard to who is in power and thus who uses (Boxer 2003: 251-277) the political properties of soundscapes to control "others". As Deleuze and Guattari (1987) argued, these positions are never constant and continously changing as the above discussions reveal that the role of sound in expressing power or suppression has significantly shifted within the last two centuries.

\section{Sound, Identity Construction, Social Segregation, and Music}

Having accepted the flexibility of not only the relation between sound and space but also of the positioning in regard to power, the potential of sound to both geopolitically (spatially, demographically) and socio-politically (socially, economically, culturally) segregated people (either by an authority to separate and control them or by the very people to resist and express their identity against authority) is further revealed.

One of the forms that sound can take to serve the purposes of power exertion, and thus, segregation on large masses of people is doubtlessly music as will be discussed below in detail. Music is inherently built in human apparatus and therefore is crucial in human behaviour. Revill (2000) argued that the distinctive properties of sound allow music to have a very particular role (of cultural authority) in the configuration of social, economic, and political spaces. Drawing examples from English music of the period 1880-1940, Revill (2000) elucidated various mechanisms in which moral geographies of landscape, nation, and citizen are informed by sound.

In fact, in addition to Revill, various scholars have studied on the role of music in determining the political context of an era. For instance, Guilbault's (2007) studies on the conduct of carnival and calypso, as well as its historical entanglements show not only 
how dance and music were implicated with nationbuilding, politics of representation, and power relationships, but also politics of identity in music and dance. Guibault refers to Foucault's notion of governmentality by viewing music as a field of social management and drawing our attention to micro-practices of power through music and soundscape via political instruments (such as bans and competitions). Gilbert and Pearson (2002), who focus on metaphysics of music, compared the meaning and pleasure (individual and communal) of tribal rites and music with the emphasis on the absence of music and dance in capitalist modernity in relation to its legacy of Puritanism. Along a similar line, Taylor (2012) suggested that after World War II to the present, music (especially popular music) has been utilised more and more for encouraging the consumption of goods and for establishing identities of certain brands in Sounds of Capitalism which focuses on the postwar upsurge in consumerism in the 1980s and after. Referring to works of Maria Pini (in politics of music and identity), George McKay (1998) elucidated radical politics of dance culture and its role in democratization of all spheres of life. Middlebrook (2011), who studies the history of prison music, said that:

Prison has been a form of political organization for the United States, at least since the beginning of the 19th century; music (or organized noise) from or about prisons helps trace this history of containment sonically. Prison music also points to the possibilities of sonic and political escape from this carceral state.

Obviously, what he calls prison music is a counter auditory reaction to the power exertion of the authority through creating an alternative soundscape. To put it in his words:

In this example of prison music, one hears sounds that confound the work that is being performed. The music makes the work illogical. It sounds like the work is not productive, at least not for the bodies performing it. This is destructive, or more precisely deconstructive, physical and sonic work: breaking down (song) structures, bodies, minds in the process. It is a sonic protest against imprisonment, even as prison labor is being performed.

Indeed, powerful songs and marches have always accompanied the significant social movements, riots, and civil conflicts. It is the rhythmic marching of specifically musical pieces that not only unites protesters but also gives them focus and resolve. Johnson and Cloonan (2008), investigated a series of social movements which utilise music as a counter-political tool for protest. For instance, well-known musician Fela Kuti introduced Afro Beat music as a means to resist against the regime of Nigeria in 1970s. His song "Zombie” was a global hit which criticized military dictators of Nigeria. Another example was the indigenous Mbatanga music that paved the way for the apartheid in South Africa. Clearly, it conveyed the message of peace and reconciliation in South Africa. Also, Victor Jara's songs about Chile's struggles, evoked the Nueva Cancion (New Songs) Movement that motivated South Americans to stand against Chilean military dictators. Similarly, songwriters like Caetano Veloso, Rita Lee, and Gilberto Gil created the Tropicalia Movement in Brazil as a type of revolt against the Brazilian military junta. Furthermore, indigenous and non-ingenious songwriters in Australia and New Zeland initiated an indigenous Land Reclamation Movement. On the other hand, however, as Johnson and Cloonan (2008) argued, alleged participation of such protest music in riots and civil conflicts also has the "cause-effect" implications. For example, Simon Bikindi, a Hutu, who purportedly incited violence against the Tutsis in Rwanda by having his songs broadcast during the genocide in his country in 1994 . Although his eventual conviction in 2008 was related to one of his speeches rather than Bikindi's music, the role of his music in the genocide was debated in detail during the trial, and was mentioned in the text of the court's decision. 
Along a similar line of argument, Nuxoll (2015) from Revolutionary United Front (RUF) in the civil war in Sierra Leone (1991-2002), suggested that music, particularly songs, played an important role in training new recruits because these songs contributed to their physical fitness and also evoked a sense of cohesion within the units, which in turn increased their readiness to battle. These songs were usually adopted from those already in use among rebel forces in Liberia. Hence, recent scholarship has already established that music is crucial in establishing identity politics, and in the formation and consolidation of social groups.

In regard to the politisation of sound for the purposes of segregating and suppressing certain classes of the society, Linebaugh (2014) gave an account of legislative measures for suppressing the working classes during the eighteenth century. For instance, according to the Riot Act of 1715, gathering in public places of a group of 12 or more people was the evidence of its violation particularly if they are noisy, riotous, tumultuous (Linebaugh 2014). Gradually, the right to impose silence over the "others" has started to define relations of power.

Thus, in regard to the politisation of human hearing mechanisms (as discussed in section 2), aforementioned cases of protests events epitomize the argument that the influence of "the mechanisms of hearing” on sound's becoming a public protest device is fully exploited through music that is performed in urban realm. Moreover, these specific events exemplify the use of sound-technologies (as mentioned along the discussion of these protests events) as counter-political strategies of soundscape against the existing power mechanisms which can be summarised as the "right to impose silence" over the "other classes" in urban realm. Thus, masses seem to have exploited the salient characteristics of sound, such as territoriality and identity, to audibly support their resistance against the power through music that is performed in public realm.

\section{CONCLUSIONS}

In sum, the role of music and street performances as sonic acts of political struggle in urban realm within the framework of the power relationships between soundscape and public space is discussed throughout the paper. With a perspective that assumes these sonic acts and their auditory dimensions as counter-political soundscapes in urban spaces, the study specifically focused on musical and performative events used as public protests. The sound and the associated soundscapes of these public events can be seen as ways of expressing communal identity within a social context whereby different parties or segments conflict and thus struggle with each other. These identities could either be associated with a social class, or with an ethnic group or a political organisation, and even sometimes with all of them.

The paper discusses the territoriality of sound as one of the attributes behind ongoing mechanisms of social segregation and polarisation. It argues sound as another means for current socio-political struggles. The study, therefore, tackles the issue of the evolution of sound into spectacles of resilient soundscapes from the perspective of the phenomenology of power-space relations. Showing the transformation of sound (in form of music and public performances) from a psychological manouvering device to a counter-political device for manipulating masses against the power, the paper puts forward the significance of the role of public music performances in protests not only as means of self-expression of identity, but also as a shield of resistance to segregation and suppression. In regard to the aforementioned debates on "positioning", the inherent power of sound seems to shift between the authority and the protesting crowds. As discussed above, examples given from world political history and recent events such as Occupy protests and Gezi protest of 2013 in Istanbul have shown the crucial role of creating a soundscape through music and public 
performances in form of spectacles in public protests against the tyranny of those in power.

Thus, it can be concluded that the capacity of soundscape to define identity is associated with the identities of minorities and opposition groups within the realm of power struggles in urban space. Particularly, the intrinsic quality of territoriality of soundscapes is further utilised by these groups to make themselves and their protest visible through varoius performances in form of spectacles as counter-political strategies against the prevailing power dominating the public realm. Here, sound technologies are deployed as a support and enhancement helping the establishment of oppositional identities against the unjust exertion of power.

\section{Notes}

1. Lester Freamon is a fictional character on the HBO drama "The Wire", played by actor Clarke Peters (Detective Freamon) as cited by Chare (2011).

2. See (https://www.rt.com/usa/337782-erdogan-security-prot est-washington/).

\section{References}

Arendt, H. 1998. The Human Condition. Chicago: University of Chicago Press.

Attali, A. 1985. Noise: The Political Economy of Music. Minneapolis: University of Minnesota Press.

Barthes, R. 1991. The Responsibility of Forms. Berkeley, CA: University of California Press.

Blesser, B. and L. Salter. 2006. Spaces Speak, Are You Listening?: Experiencing Aural Architecture. Cambridge, MA: MIT Press.

Boxer, L. 2003. "Assessment of Quality Systems With Positioning Theory.” Pp. 251-277 in The Self and Others: Positioning Individuals and Groups in Personal, Political and Cultural Contexts, edited by R. Harré and F. Moghaddam. Westport: Praeger Publishers.

Chare, N. 2011. "Policing Technology: Listening to Cop Culture in the Wire." Journal for Cultural Research 15(1):15-33.

Cluett, S. A. 2013. "Loudspeaker: Towards a Component
Theory of Media Sound.” PhD thesis, Princeton University. Davies, B. and R. Harré. 1990. "Positioning: The Discursive Production of Selves." Journal for the Theory of Social Behaviour 20(1):43-63.

Deleuze, G. and F. Guattari. 1987. A Thousand Plateaux: Capitalism and Schizophrenia. London: Athlone Press.

Damousi, J. and D. Deacon. 2007. Talking and Listening in the Age of Modernity: Essays on the History of Sound. Canberra: ANU E-Press, the Australian National University.

Foucault, M. 1980. The Eye of the Power, Power/Knowledge: Selected Interviews and Other Writings 1972/77. (Translated by C. Gordon). New York: Pantheon Books. Pp. 146-165.

Gilbert, J. and E. Pearson. 2002. Discographies: Dance, Music, Culture and the Politics of Sound. London: Routledge.

Guilbault, J. 2007. Governing Sound: Cultural Politics of Trinidad's Carnival Musics. Chicago: University of Chicago Press.

Gurney, E. (1880) 2011. The Power of Sound. Cambridge: Cambridge UP.

Hill, I. E. 2012. "Not Quite Bleeding From the Ears: Amplifying Sonic Torture." Western Journal of Communication 76(3):217-235.

Hays, G. 1992. Policewoman One: My Twenty Years on the LAPD. New York: Villard Books.

Iles, M. A., ed. 2009. Noise and Capitalism. Arteleku: Gipuzkoako Foru Aldundia.

Johnson, B. 2007. "Voice, Power and Modernity.” Pp. 113-122 in Talking and Listening in the Age of Modernity: Essays on the History of Sound, edited by J. Domousi and D. Deacon. Canberra: ANU E-Press, the Australian National University.

Johnson, B. and M. Cloonan. 2008. Dark Side of the Tune: Popular Music and Violence. Surrey: Ashgate.

Jurgenson, N. 2011. "Occupy Audio: The Soundscape of Protests.” The Atlantic. Retrieved November 28, 2011 (http://www.theatlantic.com/technology/archive/2011/11/oc cupy-audio-the-soundscape-of-protests/249123/).

Krims, A. 2007. Music and Urban Geography. New York: Routledge.

Linebaugh, P. 2014. Stop Thief! The Commons, Enclosures and Resistance. Oakland: PM Press.

McCartney, A. 2010. "Ethical Questions About Working With Soundscapes.” Soundwalking Interactions. Retrieved July 7, 2014 (http://soundwalkinginteractions.wordpress.com/201 0/06/24/ethical-questions-about-working-with-soundscapes/).

McKay, G. 1998. DIY Culture: Party and Protests in Nineties Britain. London: Verso.

McKinley, J. 2011. "At the Protests, the Message Lacks a Melody.” New York Times, October 18, 2011. 
Middlebrook, J. 2011. Prison Music: Containment, Escape, and the Sound of America. Retrieved (http://soundstudies blog.com/2011/08/22/prison-music-containment-escape-an d-the-sound-of-america/).

Mitchell, D. 2003. "The Liberalization of Free Speech: Or, How Protest in Public Space Is Silenced.” Stanford Agora: An Online Journal of Legal Perspectives 4. Retrieved July 20, 2013 (http://agora.stanford.edu/agora/volume4/mitchell. shtml).

Monaghan, J. and K. Walby. 2012. “'They Attacked the City”: Security Intelligence, the Sociology of Protest Policing and the Anarchist Threat at the 2010 Toronto G20 Summit.” Current Sociology 60(5):653-671.

Nightingale, C. 2012. Segregation: A Global History of Divided Cities. Chicago: University of Chicago Press.

Nuxoll, C. 2015. “'We Listened to It Because of the Message’: Juvenile RUF Combatants and the Role of Music in the Sierra Leone Civil War.” Music and Politics 9(1):1-25.

O’Brien, M. S. 2013. “This Is What Democracy Sounds Like: Live and Mediated Soundscapes of the Wisconsin Uprising." Music and Politics.

Parsons, D. and P. Jesilow. 2001. In the Same Voice: Women and Men in Law Enforcement. Santa Ana, CA: Seven Locks Press.

Peterson, M. 2010. Sound, Space, and the City: Civic Performance in Downtown. Los Angeles: University of Pennsylvania Press.

Pistrick, E. and I. Cyril. 2013. "Landscapes, Soundscapes, Mindscapes: Introduction.” Ethnografica 17(3):1-11.

Radovic, L. 2014. "Mic Check: Occupy Wall Street and the Space of Audition.” Communication and Critical/Cultural Studies 11(1):34-41.

Revill, G. 2000. "Music and the Politics of Sound: Nationalism, Citizenship, and Auditory Space." Environment and Planning D: Society and Space 18(5):597-613.

Schafer, R. (1977) 1994. Our Sonic Environment and the Soundscape. Vermont: Destiny Books.

Slater, H. 2009. "Prisoners of the Earth Come out! Notes
Towards 'War at the Membrane'.” Pp. 150-165 in Noise and Capitalism, edited by M. Iles. Gipuzkoako Foru Aldundia-Arteleku.

Taylor, T. 2012. The Sounds of Capitalism, Advertising, Music, and the Conquest of Culture. Chicago: University of Chicago Press.

Thompson, E. 2002. The Soundscape of Modernity: Architectural Acoustics and the Culture of Listening in America 1900-1933. Cambridge, MA: MIT Press.

Toprac, P. and A. Abdel-Meguid. 2011. "Causing Fear, Suspense, and Anxiety Using Sound Design in Computer Games.” Pp. 176-191 in Game Sound Technology and Player Interaction: Concept and Developments, edited by M. Grimshaw. Hershey, PA: IGI Global.

Toth, C. 2009. "Noise Theory." Pp. 25-37 in Noise and Capitalism, edited by Mattin and A. Iles. San Sebastián: Arteleku.

Waddington, D. and M. King. 2007. "The Impact of the Local: Police Public-Order Strategies During the G8 Justice and Home Affairs Ministerial Meetings.” Mobilization 12(4):417-430.

Zajko, M. and D. Beland. 2008. "Space and Protest Policing at International Summits." Environment and Planning D 26(6):719-735.

\section{Bios}

Konca Saher, Ph.D., assistant professor, Faculty of Arts \& Design, Dept. of Int. Architecture \& Env. Design, Kadir Has University, Cibali, Istanbul, Turkey; research fields: room and building acoustics, auralizations, archaeoacoustics and soundscape studies.

Murat Cetin, Ph.D., associate professor, Faculty of Arts \& Design, Dept. of Int. Architecture \& Env. Design, Kadir Has University, Cibali, Istanbul, Turkey; research fields: politics of urban space, urban morphology, urban transformation and urban conservation. 